Send your letters to the editor, British Dental Journal, 64 Wimpole Street, London W1G 8YS or by email tobdj@bda.org.

Priority will be given to letters less than 500 words long. Letters should be typed. Authors must sign the letter, which may be edited for reasons of space.

\section{Overseas dentists}

Sir, I was very interested to read $\mathrm{Mr}$ Townsend's response to Mr Chaudhuri on the topic of overseas dentists (BDJ 2005; 198: 253) My partner is a qualified dentist from New Zealand. She is currently working on a temporary registration in Peterborough hospital while she completes the International Qualifying Examination (IQE) so that she might be able to obtain full registration. She had already passed the required English test as well as parts A and $\mathrm{B}$ and is waiting for a date for part $\mathrm{C}$.

The reason that she has to do this is that as of 2001, New Zealand qualifications are no longer recognised by the GDC.

Previously they seemed to be regarded quite highly and all that was required was proof that they had not been struck off the register in New Zealand. Obviously something changed to the qualification in 2001 so that New Zealand dentists are no longer "properly trained, qualified and fit to practice".

It would seem to me that New Zealand dentists are the perfect answer to the shortages faced in the UK. New Zealanders primarily come to the UK with the plan of working for several years while seeing as much of Europe as possible. This means that they would help alleviate the shortage, pay a substantial amount in tax yet never collect any pensions (another area of significant shortages). If they become sick or unable to work they will more than likely return home rather than collect benefits or become a burden on the health system. More importantly New Zealand can cope far better with sending dentists overseas than many of the developing countries the GDC are currently attracting candidates from.

My partner applied for the IQE in August 2003. We estimate that by the time she has sat part $\mathrm{C}$ of the exam it will have taken approximately two years (and several thousand pounds) to gain registration. We know many New Zealand dentists who have abandoned plans to work as a dentist here for that very reason; many have even chosen to work in offices and pubs instead.

Mr Townsend is quite right that they could work under temporary registration in hospitals. Unfortunately, this isn’t particularly appealing to candidates who have been in private practice for several years. I was also under the impression that the shortage was more in general practice rather than in hospitals.

The GDC has extended the same discourtesy to Australia and Canada, whose dentists are also highly regarded, amongst others. If I was of a more cynical nature I might be inclined to think that the IQE is a nice little earner for the GDC and with nationals of the European Economic Area no longer being required to sit, they are looking to boost numbers. I struggle to see how their actions can be viewed to "protect patents" or indeed be in the interests of the British public in general.

\section{J. Fergusson}

By email

Antony Townsend, GDC Chief Executive \& Registrar responds: Thank you for the opportunity to respond to Mr Fergusson's letter to the BDJ. The General Dental Council's policy is to try to register dentists fairly, on the basis of their qualifications and competence, wherever they come from. The European legal framework within which we work does not make this easy.

Since 1 January 2002, there have been two main routes to registration with the GDC for dentists - a primary dental qualification from a dental school in the UK or European Economic Area (EEA), or passing the GDC International Qualifying Examination (IQE). In the past, the Council recognised primary dental qualifications awarded by certain dental schools outside the EEA, including New Zealand. We would periodically visit those schools to assess whether the course provided students with the scope and type of education and training relevant to the practice of dentistry in the $U K$, in much the same way as we inspect all UK dental schools on a regular basis. Dentists graduating from courses which had been GDC-approved would then be eligible to apply for GDC registration.

The Council decided to stop recognising overseas qualifications for a number of reasons. Several universities in various countries had questioned whether it was appropriate for a UK body to inspect their courses, in view of their own systems of recognition.

The GDC also recognised that it could no longer expect overseas schools to meet its revised guidelines on the dental curricula (The First Five Years) which had been developed to reflect the context in which

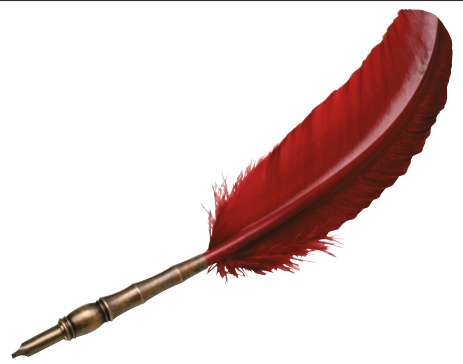

dentistry is taught and practised in the UK. Furthermore, it was inequitable to visit and approve the qualifications of some overseas dental schools, but not visit others.

The IQE aims to provide a single, fair means of testing the skills and knowledge of dentists who do not have a recognised primary dental qualification. Changes have recently been made to the examination to make it easier to deliver, without compromising its standards. It is non-profit making - it is not 'a nice little earner for the GDC'. Candidates' fees simply cover the cost of running it, which would otherwise have to be borne by current registrants through their annual retention fees.

We are shortly to undertake a review of the IQE, and the methods for assessing applicants from the EEA, to see whether further improvements can be made to assist overseas applicants for registration without compromising standards. doi: 10.1038/sj.bdj.4812476

\section{Missed diagnosis}

Sir, although there is implied criticism of the denture technician in the recent paper on an undiagnosed case of malignancy (BDJ 2005; 198: 341) the authors also make it clear that dental practitioners are sometimes culpable. Indeed, the dental profession should consider why general medical practitioners have been shown to be better at diagnosis and prompt referral than their dental colleagues - surely an embarrassing finding at the very least!

I remember a similar case being referred to me a few years ago by a suitably embarrassed general dental practitioner who admitted that he had completely missed a palatal malignancy in a similar clinical situation when the patient presented with ill-fitting dentures. It was left to the astute technician on this occasion to return the plaster model with the comment that the 'blow hole' looked a little too large to fill in, and that in his opinion it could even be a tumour! Stones and glass houses come to mind!

\section{A. E. Brown}

East Grinstead

doi: 10.1038/sj.bdj.4812477

This letter was previously printed in the BDJ as being from C. Gardener. We wish to apologise for any embarrassment caused by this error. 